\title{
Graft Photocopolymerization of Styrene with 9-Anthrylmethyl-Substituted Poly(methyl methacrylate)
}

\author{
Kenta TANAKA, ${ }^{1, \dagger}$ Hiroaki UchidA, ${ }^{2}$ Tetsutaro Igarashi, ${ }^{2}$ and Tadamitsu SAKURAI ${ }^{2}$ \\ ${ }^{1}$ High-Tech Research Center, Kanagawa University, Kanagawa-ku, Yokohama 221-8686, Japan \\ ${ }^{2}$ Department of Applied Chemistry, Faculty of Engineering, Kanagawa University, \\ Kanagawa-ku, Yokohama 221-8686, Japan
}

(Received June 2, 2005; Accepted June 28, 2005; Published October 15, 2005)

\begin{abstract}
An investigation was undertaken to achieve the graft copolymerization of styrene (St) in the presence of the 9-anthrylmethyl methacrylate/methyl methacrylate copolymer designed as a macromolecular photoinitiator. UV and ${ }^{1} \mathrm{H}$ NMR spectral analyses suggested that about $64 \%$ of the anthryl chromophore is rapidly consumed by the intramolecular cycloaddition of this chromophore. However, no additional cycloaddition occurred owing to the greatly lowered conformational mobility of polymer side chains. As a result, the homolytic $\mathrm{CH}_{2} \mathrm{O}-\mathrm{C}(=\mathrm{O})$ bond cleavage in the anthrylmethyloxycarbonyl moiety was induced to form a macroradical which initiates the polymerization of St. While the St homopolymer was produced along with the graft copolymer in our system, these two polymers were readily separated by the use of a Soxhlet extractor. [DOI 10.1295/polymj.37.754]

KEY WORDS Photopolymerization / Graft Polymerization / Radical Polymerization / Cycloaddition /
\end{abstract}

Macromolecular photoinitiator (MPI) is a subject of growing interest owing to its substantially low mobility and volatility, ${ }^{1}$ as well as to its ability to initiate graft copolymerization giving novel functional polymers. ${ }^{2-4}$ While many MPIs require the presence of coinitiator such as amines or photosensitizers in order to express their functions, there are only limited investigations regarding graft copolymerization in the absence of such a coinitiator. It was found in our previous studies that on irradiation 9-anthrylmethyloxysubstituted bichromophoric molecules undergo heterolytic and homolytic bond cleavages competitively to give ions and radicals, respectively. ${ }^{5,6}$ In addition, these bichromophoric molecules were shown to initiate cationic and radical photopolymerizations and, hence, act as novel hybrid-type photoinitiators though their initiation abilities are low.

On the other hand, 9-anthrylmethyloxycarbonyl and related chromophores have been utilized as probes for elucidating photophysical and photochemical behavior of a given chromophore introduced into methyl methacrylate-derived homo- and copolymers. ${ }^{7-10} \mathrm{~A}$ literature survey reveals that there is no systematic study on the ability of copolymer to initiate radical or ionic polymerization, namely, the ability in MPI. It is likely that the 9-anthrylmethyl methacrylate (AMMA)/methyl methacrylate (MMA)-derived copolymer shows a photochemical behavior similar to that of 9-anthrylmethyl acetate. ${ }^{6}$ If so, this copolymer would function as one of the coinitiator-free MPIs. Taking into account the well-known fact that the anthracene chromophore has a strong tendency to undergo a photocycloaddition reaction (photocrosslinking reaction), ${ }^{11,12}$ we designed AMMA/MMAderived copolymer so as to keep the distance between anthracene pendants relatively long and investigated the ability of this copolymer to initiate the graft copolymerization of St.

\section{EXPERIMENTAL}

\section{Materials}

According to the previously described procedure, ${ }^{13}$ AMMA was prepared by the reaction of anthracene9-methanol with methacryloyl chloride in the presence of triethylamine in chloroform. The crude product was purified by column chromatography over silica gel (70-230 mesh) using chloroform and hexane as the eluent, followed by recrystallization from ethanol. As model compounds of the AMMA/MMA copolymer, 9-anthrylmethyl isopropanoate (AI) and bis(9-anthrylmethyl) glutarate (BAG) were prepared according to the same procedure as above.

9-Anthrylmethyl methacrylate (AMMA): Yield 61\%; mp 84.5-86.0 ${ }^{\circ} \mathrm{C}$. IR (KBr): v 2925, 1707, 1622, $1453,1155,1148 \mathrm{~cm}^{-1} .{ }^{1} \mathrm{H}$ NMR $\left(500 \mathrm{MHz}, \mathrm{CDCl}_{3}\right)$ : $\delta 1.92(\mathrm{~s}, 3 \mathrm{H}), 5.51(\mathrm{~s}, 1 \mathrm{H}), 6.06(\mathrm{~s}, 1 \mathrm{H}), 6.23(\mathrm{~s}, 2 \mathrm{H})$, $7.50(\mathrm{dd}, J=8.0,8.2 \mathrm{~Hz}, 2 \mathrm{H}), 7.58(\mathrm{dd}, J=8.0,8.9$ $\mathrm{Hz}, 2 \mathrm{H}), 8.04(\mathrm{~d}, J=8.2 \mathrm{~Hz}, 2 \mathrm{H}), 8.38(\mathrm{~d}, J=8.9 \mathrm{~Hz}$, 2H), $8.53(\mathrm{~s}, 1 \mathrm{H}) .{ }^{13} \mathrm{C} \mathrm{NMR}\left(125 \mathrm{MHz}, \mathrm{CDCl}_{3}\right): \delta$ $18.3,59.1,124.0$ (2C), 125.1 (2C), 126.0, 126.4, 126.6 (2C), 129.07 (2C), 129.12 (2C), 131.1 (2C), 131.4,

${ }^{\dagger}$ To whom correspondence should be addressed (E-mail: kentat@k9.dion.ne.jp). 
Graft Photopolymn. Using 9-Anthrylmethyl-Substituted Polymer

Table I. Radical copolymerization of AMMA with MMA in toluene

\begin{tabular}{|c|c|c|c|c|c|c|c|}
\hline \multirow[b]{2}{*}{ Initiator $^{\mathrm{a})}$} & \multirow[b]{2}{*}{$\frac{[\mathrm{AMMA}]}{[\mathrm{MMA}]}$} & \multirow{2}{*}{$\begin{array}{c}\text { Temp. } \\
\left({ }^{\circ} \mathrm{C}\right)\end{array}$} & \multirow{2}{*}{$\begin{array}{l}\text { Time } \\
\text { (h) }\end{array}$} & \multicolumn{4}{|c|}{ Copolymer } \\
\hline & & & & $\frac{[\mathrm{AMMA}]}{[\mathrm{MMA}]}$ & $\begin{array}{l}\text { Yield } \\
(\%)\end{array}$ & $M_{\mathrm{n}} \times 10^{-4}$ & $M_{\mathrm{w}} / M_{\mathrm{n}}$ \\
\hline AIBN & $5 / 95$ & 60 & 6 & $5 / 95$ & 77 & 2.3 & 1.7 \\
\hline $\mathrm{ACN}$ & $20 / 80$ & 80 & 6 & $20 / 80$ & 40 & 3.6 & 4.0 \\
\hline $\mathrm{ACN}$ & $20 / 80$ & 80 & 12 & $20 / 80$ & 94 & 3.0 & 2.7 \\
\hline
\end{tabular}

${ }^{\mathrm{a}}[$ Initiator $]=50 \mathrm{mmol} \mathrm{dm}^{-3},[\mathrm{AMMA}]+[\mathrm{MMA}]=2.0 \mathrm{~mol} \mathrm{dm}^{-3}$.

136.2, 167.6. Analysis: calculated for $\mathrm{C}_{19} \mathrm{H}_{16} \mathrm{O}_{2}$ : C, 82.47\%; H, 5.84\%; found: C, $82.47 \%$; H, 5.97\%.

9-Anthrylmethyl isopropanoate (AI): Yield 11\%; $\mathrm{mp}$ 95.0-96.0 ${ }^{\circ} \mathrm{C}$. IR (KBr): v 1728, $1150 \mathrm{~cm}^{-1}$. ${ }^{1} \mathrm{H}$ NMR $\left(500 \mathrm{MHz}, \mathrm{CDCl}_{3}\right): \delta 1.54(\mathrm{~d}, J=6.8 \mathrm{~Hz}$, $6 \mathrm{H}), 2.57(\mathrm{q}, J=6.8 \mathrm{~Hz}, 1 \mathrm{H}), 6.13(\mathrm{~s}, 2 \mathrm{H}), 7.49$ $(\mathrm{dd}, J=6.8,8.2 \mathrm{~Hz}, 2 \mathrm{H}), 7.57(\mathrm{dd}, J=6.8,8.9 \mathrm{~Hz}$, $2 \mathrm{H}), 8.03(\mathrm{~d}, J=8.2 \mathrm{~Hz}, 2 \mathrm{H}), 8.33(\mathrm{~d}, J=8.9 \mathrm{~Hz}$, $2 \mathrm{H}), 8.51(\mathrm{~s}, 1 \mathrm{H}),{ }^{13} \mathrm{C} \mathrm{NMR}\left(125 \mathrm{MHz}, \mathrm{CDCl}_{3}\right): \delta$ 19.0(2C), 34.1, 58.8, 124.0(2C), 125.1(2C), 126.50, 126.54(2C), 129.0(2C), 129.1(2C), 131.1, 131.4(2C), 177.4. Analysis: calculated for $\mathrm{C}_{19} \mathrm{H}_{18} \mathrm{O}_{2}: \mathrm{C}, 81.99 \%$; $\mathrm{H}, 6.52 \%$; found: $\mathrm{C}, 82.32 \%$; $\mathrm{H}, 6.62 \%$.

Bis(9-anthrylmethyl) glutarate (BAG): Yield 59\%; mp $160.0-161.0^{\circ} \mathrm{C}$. IR (KBr): v 1724, $1134 \mathrm{~cm}^{-1}$. ${ }^{1} \mathrm{H}$ NMR $\left(500 \mathrm{MHz}, \mathrm{CDCl}_{3}\right): \delta 1.95(\mathrm{dd}, J=7.4$, $7.4 \mathrm{~Hz}, 2 \mathrm{H}), 2.35(\mathrm{dd}, J=7.4,7.4 \mathrm{~Hz}, 4 \mathrm{H}), 6.11(\mathrm{~s}$, $4 \mathrm{H}), 7.45(\mathrm{dd}, J=8.0,7.7 \mathrm{~Hz}, 4 \mathrm{H}), 7.51(\mathrm{dd}, J=7.7$, $8.6 \mathrm{~Hz}, 4 \mathrm{H}), 8.00(\mathrm{~d}, J=8.0 \mathrm{~Hz}, 4 \mathrm{H}), 8.28(\mathrm{~d}, J=8.6$ $\mathrm{Hz}, 4 \mathrm{H}), 8.48$ (s, 2H). ${ }^{13} \mathrm{C}$ NMR $\left(125 \mathrm{MHz}, \mathrm{CDCl}_{3}\right)$ : $\delta$ 20.1, 33.2(4C), 58.8(2C), 123.9(4C), 125.1(4C), 126.1(2C), 126.6(4C), 129.1(4C), 129.2(2C), 131.0(4C), 131.3(2C), 173.1(2C). Analysis: calculated for $\mathrm{C}_{35^{-}}$ $\mathrm{H}_{28} \mathrm{O}_{4}$ : C, $82.01 \%$; $\mathrm{H}, 5.51 \%$; found: $\mathrm{C}, 81.87 \% ; \mathrm{H}$, $5.58 \%$.

Commercially available MMA and St were distilled under reduced pressure before use. 2,2'-Azobisisobutyronitrile (AIBN) and 1,1'-azobis(cyclohexane-1carbonitrile) (ACN) were recrystallized from methanol. Toluene was purified by the conventional method.

\section{Polymerization Procedures}

Thermal copolymerization of AMMA with MMA was carried out in a degassed and sealed glass tube. The polymerization mixture was poured into $n$-hexane and the resulting precipitate was dried in vacuo at $40^{\circ} \mathrm{C}$. Photopolymerization of St in the presence of the AMMA/MMA copolymer $\left(\mathrm{MPI}_{\mathrm{Ant}}\right)$ was carried out in a degassed and sealed glass tube with light of wavelengths longer than $340 \mathrm{~nm}$ from a $500 \mathrm{~W}$ highpressure mercury lamp (Corning 0-52 and Toshiba IRA-25S glass filters). The irradiation light intensity was $170 \mathrm{~mW} \mathrm{~cm}^{-2}$. The polymerization mixture was poured into aqueous methanol and the resulting precipitate was dried in vacuo at $40^{\circ} \mathrm{C}$.

\section{Photoirradiation of $M P I_{A n t}, A I$, and $B A G$}

A toluene solution of $\mathrm{MPI}_{\mathrm{Ant}}$, AI, or BAG was irradiated with light of wavelengths longer than $340 \mathrm{~nm}$ from a $450 \mathrm{~W}$ high-pressure mercury lamp (Corning 0-52 and Toshiba IRA-25S glass filters). The irradiation light intensity was $3.0 \mathrm{~mW} \mathrm{~cm}{ }^{-2}$ in this case.

\section{Measurements}

The molecular weight distribution of the polymer was measured with a Tosoh 8000 series gel permeation chromatography (GPC) system equipped with a TSKgel Mutipore $\mathrm{XL}_{\mathrm{XL}}-\mathrm{M} \times 2$ at $40^{\circ} \mathrm{C}$. A calibration curve from 500 to $1.11 \times 10^{6}$ was obtained by using the standard polystyrene (polySt). ${ }^{1} \mathrm{H}$ and ${ }^{13} \mathrm{C}$ NMR spectra were recorded on a JEOL JNM-A500 spectrometer at 500 and $125 \mathrm{MHz}$, respectively. Tetramethylsilane was employed as an internal standard. UV spectra were taken with a Hitachi U-3300 spectrophotometer. The irradiation light intensity was determined by the use of an ORC UV-M03 intensity meter equipped with a UV-SN35-M10 photodetector (Tokyo, Japan).

\section{RESULTS AND DISCUSSION}

\section{Copolymerization of AMMA with MMA}

As described in the Introduction, there remains the possibility that photocycloaddition between anthracene chromophores in the AMMA/MMA copolymer occurs in competition with the graft photocopolymerization of this copolymer with St. It is, thus, preferable to minimize the contribution of the undesirable cycloaddition. For this end, the AMMA/MMA mole ratio was allowed to be less than $1 / 5$. As shown in Table I, the reaction of AMMA with MMA under some conditions gave the corresponding copolymer in high yield, and the ${ }^{1} \mathrm{H}$ NMR spectrum of this copolymer was depicted in Figure 1. The copolymer composition was estimated from the area ratio of the aryl and methoxy methyl proton signals. As a MPI ${ }_{\text {Ant }}$ for the graft copolymerization of $\mathrm{St}$, we employed the AMMA/ MMA copolymer $\left(M_{\mathrm{n}}=3.0 \times 10^{4}\right)$ obtained from the reaction mixture heated for $12 \mathrm{~h}$ at $80^{\circ} \mathrm{C}$. The average number of 9-anthrylmethyloxycarbony group in $\operatorname{MPI}_{\text {Ant }}\left(N_{\text {Ant }}=44\right)$ was calculated from the $M_{\mathrm{n}}$, the 


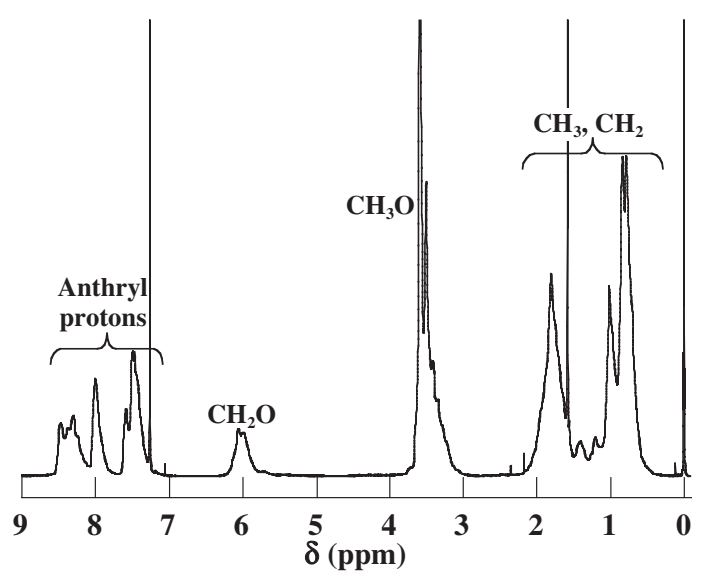

Figure 1. ${ }^{1} \mathrm{H}$ NMR spectrum of the AMMA/MMA copoly$\operatorname{mer}\left(M_{\mathrm{n}}=3.0 \times 10^{4}\right)$ in $\mathrm{CDCl}_{3}$.

copolymer composition ([AMMA]/([AMMA] + $[\mathrm{MMA}])=0.20)$ of $\mathrm{MPI}_{\mathrm{Ant}}$, and the molecular weights of AMMA $\left(M_{\mathrm{a}}=276\right)$ and MMA $\left(M_{\mathrm{m}}=\right.$ 100) by using the following equation: $\{30000 /[0.20 \times$ $\left.\left.M_{\mathrm{a}}+(1-0.20) \times M_{\mathrm{m}}\right]\right\} \times 0.20=N_{\text {Ant }}$. The average number of MMA unit in $\operatorname{MPI}_{\text {Ant }}\left(N_{\mathrm{M}}=176\right)$ was estimated similarly based on the value: [MMA]/ $([$ AMMA $]+[$ MMA] $])=0.80$.

Scheme 1 shows a plausible initiation mechanism in the St photopolymerization where MPI $\mathrm{Ant}_{\text {t }}$ was used as a macroinitiator. It is possible that the anthrylmethyloxycarbonyl moiety undergoes the homolytic $\mathrm{CH}_{2} \mathrm{O}-\mathrm{C}(=\mathrm{O})$ bond cleavage as well as the heterolytic $\mathrm{CH}_{2}-\mathrm{O}$ bond cleavage in its excited singlet state, as demonstrated from such competitive homolytic and heterolytic bond cleavages caused by the irradiation of 9-anthrylmethyl acetate in methanol. ${ }^{6}$ On the other hand, the recent finding that the photolysis of 9antherylmethyl 4-methylbenzoate in the nonpolar
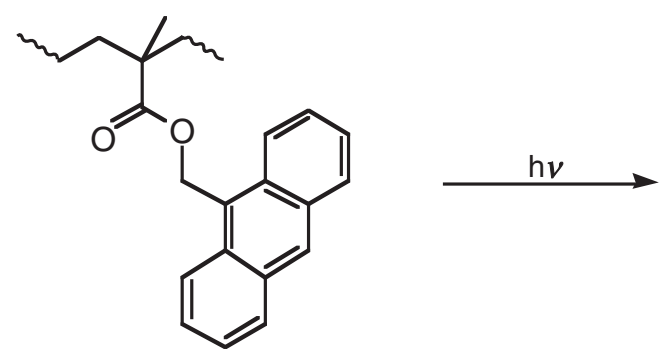

Macro radical

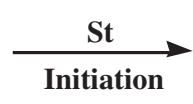

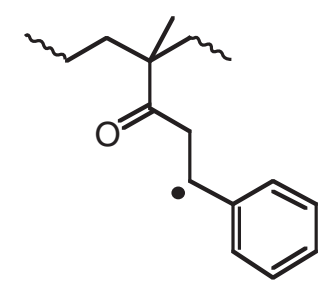

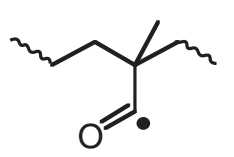

Macro radical

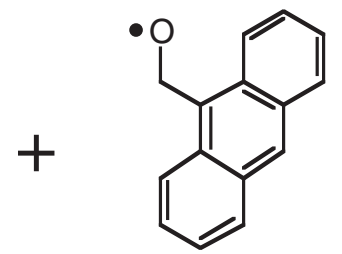

Anthrylmethyloxyl radical solvent, toluene, generates predominantly radical derived products ${ }^{14}$ strongly suggests that in St (of polarity being comparable to that of toluene) the $\mathrm{CH}_{2} \mathrm{O}-$ $\mathrm{C}(=\mathrm{O})$ bond in $\mathrm{MPI}_{\mathrm{Ant}}$ undergoes its homolysis in the excited singlet state yielding macroradical and anthrylmethyloxyl radical. The former radical enables the initiation of St polymerization via addition to the $\mathrm{C}=\mathrm{C}$ double bond in St. It is likely that the addition of the latter radical to this double bond is not so fast owing to its oxyl radical nature. ${ }^{15}$

In Figure 2(a) are shown UV absorption spectral changes caused by the irradiation $(\lambda>340 \mathrm{~nm})$ of MPI ${ }_{\text {Ant }}$ in toluene at room temperature. This figure also contains UV spectral changes in the model compounds, BAG and AI, irradiated under the same conditions [Figures 2(b) and 2(c)]. Because BAG contains two anthrylmethyloxycarbonyl groups at the near position, these groups have a strong tendency to undergo a photocycloaddition reaction. In contrast, AI has only one anthrylmethyloxycarbonyl group and its concentration is sufficiently low, so that the cycloaddition is very unlikely to occur efficiently. In addition, in these two model compounds the $\mathrm{CH}_{2} \mathrm{O}-\mathrm{C}(=\mathrm{O})$ bond cleavage proceeds at almost the same rate and also with low efficiencies. ${ }^{6}$ A difference in these reaction efficiencies may be clearly reflected in a difference in the decay rates of UV absorption spectra: namely, less efficient photoreaction exhibits slower UV spectral changes. As seen from Figure 2, on irradiation BAG shows fast UV spectral changes but AI does not, being consistent with our expectation. Thus, the finding that $\mathrm{MPI}_{\mathrm{Ant}}$ gives rapid UV spectral changes at the early stage of the reaction and then much slower spectral changes are observed after 5 min irradiation confirms that both the photocycloaddition and the less efficient $\mathrm{CH}_{2} \mathrm{O}-\mathrm{C}(=\mathrm{O})$ bond cleavage in the
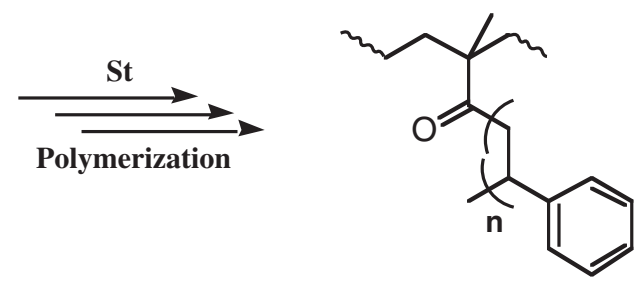

Scheme 1. 

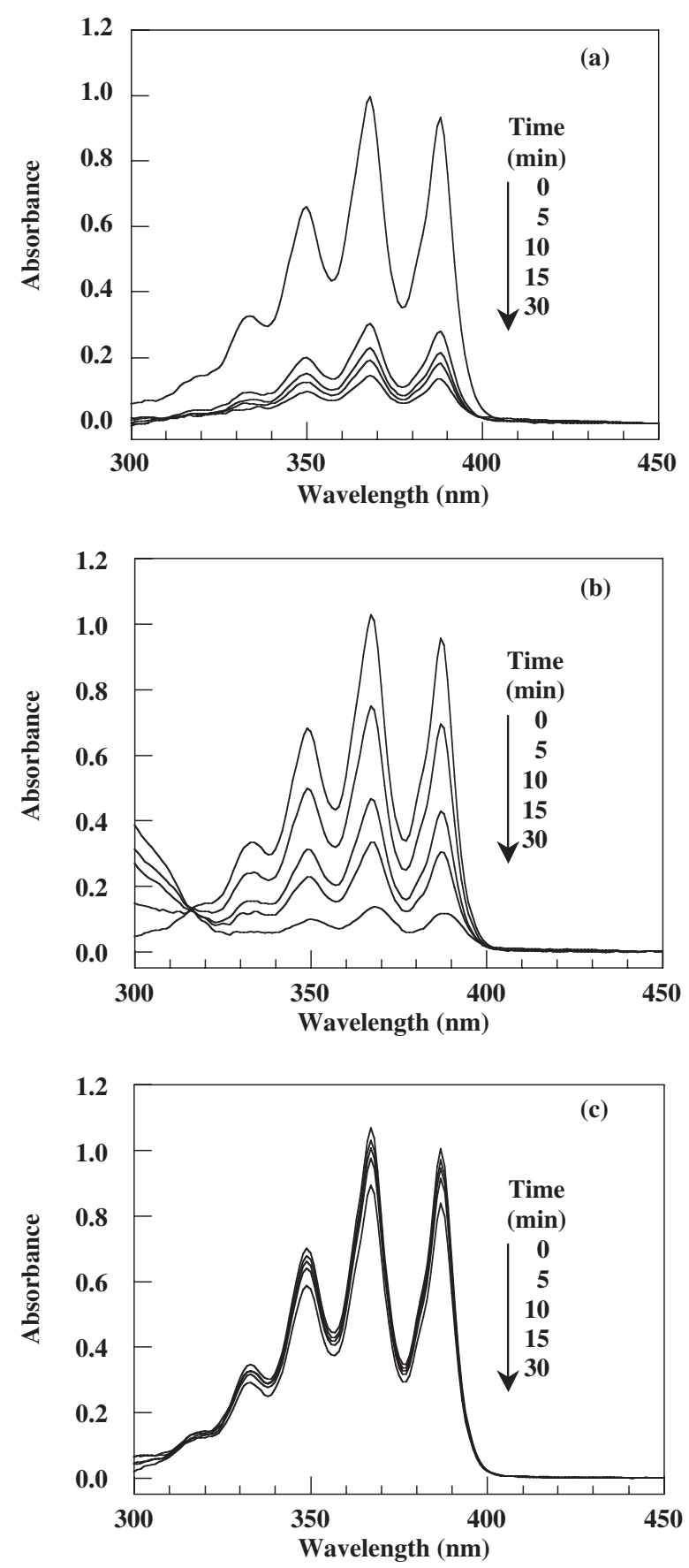

Figure 2. UV absorption spectral changes of MPI $\mathrm{Ant}_{\text {(spectra }}$ a, $69 \mathrm{~g} \mathrm{dm}^{-3}$ ), BAG (spectra b, $5.0 \times 10^{-5} \mathrm{~mol} \mathrm{dm}^{-3}$ ), and AI (spectra c, $1.0 \times 10^{-4} \mathrm{~mol} \mathrm{dm}^{-3}$ ), caused by their irradiations in toluene.

anthrylmethyloxycarbonyl moiety proceed competitively. It is worthwhile to note here that the intramolecular photocycloaddition of the anthracene chromophore is responsible for the decreased conformational mobility of this chromophore in $\mathrm{MPI}_{\mathrm{Ant}}$.

Our attention is now directed to ${ }^{1} \mathrm{H}$ NMR spectral changes caused by the irradiation of $\mathrm{MPI}_{\mathrm{Ant}}$ in toluene at room temperature. As depicted in Figure 3, on the spectrum recorded after $5 \mathrm{~min}$ irradiation the area of the anthryl-substituted methyloxy proton signal

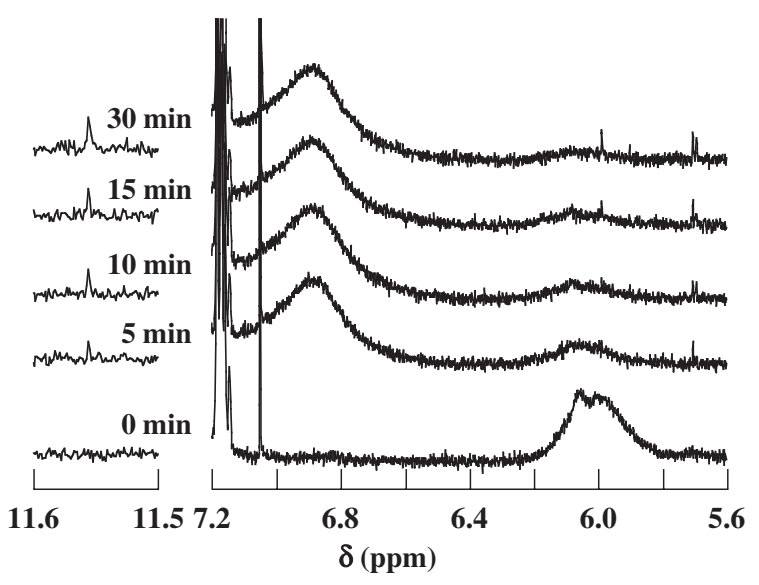

Figure 3. ${ }^{1} \mathrm{H} \mathrm{NMR}$ spectra of $\mathrm{MPI}_{\mathrm{Ant}}$ in $\mathrm{CDCl}_{3}$, measured before and after its irradiation. A toluene solution of $\mathrm{MPI}_{\mathrm{Ant}}(69$ $\mathrm{g} \mathrm{dm}^{-3}$ ) was prepared and irradiated. After its irradiation, toluene was evaporated to dryness and the resulting residue was dissolved in $\mathrm{CDCl}_{3}$ for ${ }^{1} \mathrm{H} \mathrm{NMR}$ spectral measurements.

Table II. Graft photopolymerization of St with $\mathrm{MPI}_{\text {Ant }}{ }^{\text {a }}$

\begin{tabular}{cccc}
\hline Time $(\mathrm{h})$ & Yield $\left(\mathrm{g} \mathrm{dm}^{-3}\right)$ & $M_{\mathrm{n}} \times 10^{-4}$ & $M_{\mathrm{w}} / M_{\mathrm{n}}$ \\
\hline 2 & 18 & 2.5 & 11.0 \\
4 & 21 & 2.2 & 7.0 \\
8 & 48 & 1.7 & 3.9 \\
16 & 56 & 2.9 & 8.4 \\
\hline${ }^{\mathrm{a}}\left[\mathrm{MPI}_{\text {Ant }}\right]=13 \mathrm{~g} \mathrm{dm}^{-3}$, & {$[\mathrm{St}]=2.0 \times 10^{-3} \mathrm{~mol} \mathrm{dm}^{-3}=$} \\
$2.1 \times 10^{2} \mathrm{~g} \mathrm{dm}^{-3}$ in toluene at $60^{\circ} \mathrm{C}$. &
\end{tabular}

(detected at $6.0 \mathrm{ppm}$ ) was decreased up to $36 \%$ of the initial area, while a signal assignable to cycloaddition product-derived aromatic proton was observed at 6.9 ppm. ${ }^{16}$ These observations substantiate our proposal that about $64 \%$ of the AMMA unit undergoes the photocycloaddition described above and the remaining AMMA unit does homolytic bond cleavage to eventually give anthracenecarbaldehyde, the characteristic signal of which can be detected at $11.55 \mathrm{ppm}$.

\section{Photoinitiation Ability}

The results obtained by the photopolymerizations of St with MPI Ant $_{\text {as a macroinitiator are summarized }}$ in Table II. The polymer yield is clearly increased with irradiation time, indicating that $\mathrm{MPI}_{\mathrm{Ant}}$ acts as a macromolecular photoinitiator. Since the concentration of this initiator was adjusted so as to minimize the contribution of intermolecular photocycloaddition between the anthracene chromophores, the enhanced concentration of $\mathrm{MPI}_{\mathrm{Ant}}$ is very likely to result in an increase in polymer yield. In addition, the finding that the presence of TEMPO $\left(0.10 \mathrm{~mol} \mathrm{dm}^{-3}\right)$ inhibits the photopolymerization almost completely substantiates the participation of radical-initiated polymerization reaction (Scheme 1).

An analysis of the molecular-weight distribution 


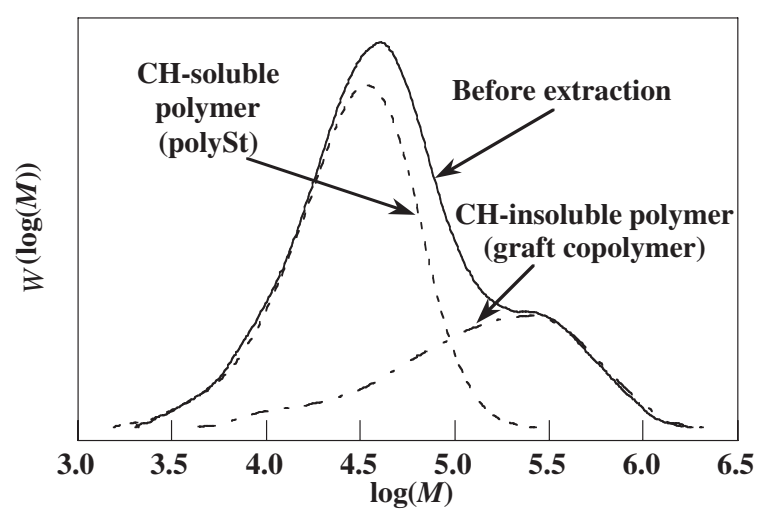

Figure 4. GPC elution curves of polymers obtained by the $16 \mathrm{~h}$ irradiation $(\lambda>340 \mathrm{~nm})$ at $60^{\circ} \mathrm{C}$ of St $\left(2.0 \times 10^{-3} \mathrm{~mol} \mathrm{dm}^{-3}\right)$ in the presence of $\mathrm{MPI}_{\mathrm{Ant}}\left(13 \mathrm{~g} \mathrm{dm}^{-3}\right)$ in toluene. Cyclohexane is abbreviated as $\mathrm{CH}$.

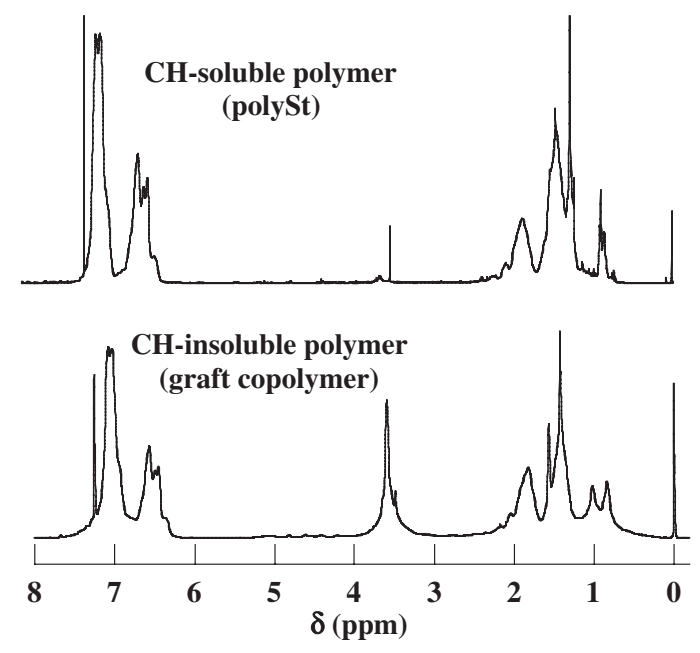

Figure 5. ${ }^{1} \mathrm{H} \mathrm{NMR}$ spectra of $\mathrm{CH}$-soluble and $\mathrm{CH}$-insoluble polymers in $\mathrm{CDCl}_{3}$. The polymer mixture was obtained by the $16 \mathrm{~h}$ irradiation $(\lambda>340 \mathrm{~nm})$ at $60^{\circ} \mathrm{C}$ of St $\left(2.0 \times 10^{-3}\right.$ mol dm$\left.{ }^{-3}\right)$ in the presence of MPI $_{\text {Ant }}\left(13 \mathrm{~g} \mathrm{dm}^{-3}\right)$ in toluene.

curve of polymer obtained by $16 \mathrm{~h}$ irradiation, depicted in Figure 4, reveals that this curve is bimodal and, hence, is consistent with the presence of the St homopolymer which would be formed via hydrogen abstraction of the 9-anthrylmethyloxyl radical from a solvent molecule. In order to separate the St homopolymer from the polymer mixtures containing poly(AMMA-co-MMA)-graft-poly(St), the Soxhlet extraction was performed using cyclohexane $(\mathrm{CH})$ which is a good solvent for poly(St) but a poor solvent for poly(MMA). The $M_{\mathrm{n}}$ value of $\mathrm{CH}$-soluble polymer $\left(2.0 \times 10^{4}\right)$ was found to be smaller than that of $\mathrm{CH}$ insoluble polymer $\left(7.0 \times 10^{4}\right)$, as shown in resolved GPC elution curves (Figure 4). The ${ }^{1} \mathrm{H}$ NMR spectra of these $\mathrm{CH}$-soluble and $\mathrm{CH}$-insoluble polymers are shown in Figure 5. Because in the former spectrum there are signals assigned to the phenyl (6.4-7.4 $\mathrm{ppm})$ and methylene (0.8-2.1 ppm) protons but no methoxy methyl proton signals, the $\mathrm{CH}$-soluble polymer is attributable to the St homopolymer. On the other hand, the latter $\mathrm{CH}$-insoluble polymer exhibits the phenyl proton signals around 6.4-7.4 ppm (St unit) and the methoxy methyl proton signals around 3.4$3.9 \mathrm{ppm}$ (MMA unit). Additionally, the $M_{\mathrm{n}}$ value for the latter polymer was found to be larger than that for MPI $_{\text {Ant }}$. These findings, therefore, led us to conclude that the $\mathrm{CH}$-insoluble polymer is the graft copolymer, poly(AMMA-co-MMA)-graft-poly(St).

Acknowledgment. This research was partially supported by a "High-Tech Research Project" from the Ministry of Education, Culture, Sports, Science and Technology, Japan.

\section{REFERENCES}

1. J. V. Crivello and K. Dietliker, "Photoinitiators for Free Radical Cationic \& Anionic Photopolymerisation, Volume 3," John Wiley \& Sons, Inc., New York, 1998.

2. T. Sato, R. Maeda, M. Seno, and T. Hirano, Eur. Polym. J., 38, 1491 (2002).

3. Y. Ma, G. Wu, and W. Yang, J. Macromol. Sci., Pure Appl. Chem., A40, 1147 (2003).

4. R. Francis and A. Ajayaghosh, Macromolecules, 33, 4699 (2000).

5. K. Tanaka, K. Nakamura, N. Yoshioka, A. Kameyama, T. Igarashi, and T. Sakurai, J. Polym. Sci., Part A: Polym. Chem., 42, 2859 (2004).

6. K. Tanaka, Y. Takahashi, T. Isobe, T. Satoh, R. Akimoto, T. Igarashi, and T. Sakurai, J. Photochem. Photobiol., A in press.

7. C. I. Simionescu, M. Grigoras, and G. Onofrei, Makromol. Chem., 186, 1121 (1985).

8. J. Ferreira De Deus, M. L. Andrade, T. D. Z. Atvars, and L. Akcelrud, Chem. Phys., 297, 177 (2004).

9. S. P. Kozel, G. I. Lashkov, M. G. Krakovyak, M. G. Shelekhov, and S. S. Skorokhodov, Khim. Fiz., 4, 56 (1985).

10. J. S. Hargreaves, J. Polym. Sci., Part A: Polym. Chem., 27, 203 (1989).

11. H. Bouas-Laurent, J.-P. Desvergne, A. Castellan, and R. Lapouyade, Chem. Soc. Rev., 29, 43 (2000).

12. H. Bouas-Laurent, J.-P. Desvergne, A. Castellan, and R. Lapouyade, Chem. Soc. Rev., 30, 248 (2001).

13. D. A. Holden and J. E. Guillet, Macromolecules, 13, 289 (1980).

14. K. Tanaka, R. Akimoto, T. Igarashi, and T. Sakurai, Unpublished result.

15. J. Fossey, D. Lefort, and J. Sorba, "Free Radicals in Organic Chemistry," John Wiley \& Sons, Chichester, 1995.

16. H.-D. Becker and V. Langer, J. Org. Chem., 58, 4703 (1993). 